\title{
Effects of granulocyte colony-stimulating factor and granulocyte-macrophage colony-stimulating factor on lung cancer: Roles of cyclooxygenase-2
}

\author{
YOSHIKI UEMURA, MAKOTO KOBAYASHI, HIDESHI NAKATA, TETSUYA KUBOTA, \\ TSUYAKO SAITO, KENTARO BANDOBASHI and HIROKUNI TAGUCHI
}

Department of Internal Medicine, Kochi University of Medicine, Kochi, Japan

Received November 7, 2006; Accepted December 11, 2006

\begin{abstract}
We examined the effects of granulocyte colonystimulating factor (G-CSF) and granulocyte-macrophage colony-stimulating factor (GM-CSF) on the lung cancer cell lines PC-9, LA-1 and A549. In addition, we examined if the effects of the cytokines on the cell lines are mediated by activation of cyclooxygenase (COX)-2. The three cell lines did not constitutively produce either G-CSF or GM-CSF. G-CSF did not influence cell growth in the three cell lines, while GM-CSF increased cell growth in the A549 and LA-1 lines. G-CSF and GM-CSF dose-dependently decreased cell death in the three cell lines. RT-PCR demonstrated GM-CSF receptor expression in the three lung cancer cell lines, whereas the G-CSF receptor exists only in the PC-9 line. We suggest that G-CSF might rescue the tumor cells from cytotoxicity due to serum deprivation through cellular pathways independent of the G-CSF receptor. G-CSF and GM-CSF increased cyclooxygenase-2 (COX-2) expression in PC-9 and LA-1 cells whereas they decreased COX-2 expression in A549 cells. The COX-2 inhibitor NS-398 increased cell death in PC-9 and LA-1 cells, whereas it decreased cell death in A549 cells. PC-9 and LA-1 clones transfected with sense G-CSF- or GM-CSF showed an increase in COX-2 expression, while COX-2 expression was decreased in transfected A549 clones. COX-2 expression was increased in anti-sense G-CSF- and GM-CSF-transfected A549 clones. Thus, although COX-2 activation seems to induce different biological behavior depending on the cell type, we propose that G-CSF and GMCSF might accelerate tumor progression by directly regulating COX-2 expression, independently of an autocrine mechanism.
\end{abstract}

Correspondence to: Dr Yoshiki Uemura, Department of Internal Medicine, Kochi Medical School, Kohasu, Okocho, Nankoku, Kochi 783-8505, Japan

E-mail: uemuray@med.kochi-u.ac.jp

Key words: cyclooxygenase-2, granulocyte colony-stimulating factor, granulocyte-macrophage colony-stimulating factor, lung cancer

\section{Introduction}

A significantly increased expression of cyclooxygenase-2 (COX-2) is frequently seen in a specific type of lung cancer (i.e., adenocarcinoma), in contrast to the scattered weak reactivity seen in normal peripheral airway epithelial cells. Such an increase in COX-2 expression may be a clinically significant prognostic factor for patients undergoing surgical resection of early-stage adenocarcinomas $(1,2)$. Some COX-2 inhibitors induce growth inhibition and apoptosis, indicating that increased COX-2 activity is closely associated with tumor growth in lung cancer (3). In advanced clinical stages, many cases of lung cancer constitutively produce colony-stimulating factors (CSFs), including granulocyte colony-stimulating factor (G-CSF), granulocyte-macrophage colony-stimulating factor (GM-CSF), in amounts large enough to cause a significant systemic hematopoietic effect (4-6). The prognosis is significantly worse in patients with non-small cell lung cancer (NSCLC) showing G-CSF gene expression (7). Some studies suggest that CSFs produced by lung cancer cells might promote tumor progression via an autocrine mechanism $(8,9)$. However, G-CSF-producing lung tumor cells do not necessarily have G-CSF receptors (10). We hypothesize that G-CSF might promote tumor progression through a mechanism separate from an autocrine growth loop. We previously reported that a COX-2 inhibitor decreases constitutive production of G-CSF and GM-CSF from lung cancer cells, resulting in inhibition of cell growth (11). These data suggested that the effects of G$\mathrm{CSF}$ and GM-CSF on the tumor progression might be closely associated with COX-2 activity in the lung cancer with an autocrine growth loop. In this study, we also examined the effects of G-CSF and GM-CSF on biological behavior in lung cancer cells not constitutively producing G-CSF and GM-CSF. Our results show that G-CSF and GM-CSF influence COX-2 expression in the lung cancer cells, resulting in increased cell growth or inhibition of cell death. G-CSF especially inhibited cell death via COX-2 activation, even in lung cancer cells without G-CSF receptors.

\section{Materials and methods}

Reagents and supplies. Enzyme-linked immunosorbent assay (ELISA) kits for measuring the contents of G-CSF and GMCSF in culture medium were from TECHNE (Minneapolis, 
$\mathrm{MN})$. The extracellular matrix (ECM) cell invasion assay kit was obtained from Chemicon (Temecula, CA). Recombinant human G-CSF and GM-CSF were obtained from Sigma (St. Louis, MO). Anti-human G-CSF antibody (Ab), antihuman GM-CSF Ab, mouse IgG1 isotype control and normal goat IgG were purchased from R\&D Systems (Minneapolis, MN). Rabbit anti-neomycin phosphotransferase II Ab was purchased from Upstate Biotechnology (Lake Placid, NY). Mouse anti-COX-2 Ab was purchased from BD Biosciences (Franklin Lakes, NJ). The 'Cell Titer 96' AQueous one solution cell proliferation assay kit and the 'Cyto Tox 96' non-radioactive cytotoxicity assay kit were purchased from Promega (Madison, WI). The MiraClean endotoxin removal kit (Mirus, WI) and TransIT ${ }^{\circledR}$-LT1 transfection reagent were obtained from Mirus (Madison, WI). Human G-CSF cDNA in pBRV2 was kindly provided by Chugai Pharmaceutical Co. (Tokyo, Japan) and human GM-CSF cDNA in pCSF-1 was obtained from American Type Culture Collection (Manassas, VA). Empty expression vector pUSEamp was purchased from Upstate Biotechnology. N-[2-(cyclohexyloxy)-4-nitrophenyl]methanesulfonamide (NS-398) was purchased from Alexis Biochemicals (San Diego, CA). NS-398 was prepared in dimethyl sulphoxide (DMSO) as a 1000X stock and was handled in subdued light conditions.

Cell lines. A549, PC-9 and LA-1 lung cancer cell lines were used and maintained in Dulbeco's modified Eagle's medium (DMEM) containing $10 \%$ fetal calf serum (FCS) at $37^{\circ} \mathrm{C}$ in an incubator under a $100 \%$ humidified $5 \% \mathrm{CO}_{2}$ atmosphere. The PC-9 cell line was kindly provided by Professor Jiro Hujita (Ryukyu University, Okinawa, Japan). The LA-1 cell line was established from a patient with large cell carcinoma in our laboratory. Subcultures were carried out twice weekly by removing the cells from $75 \mathrm{~cm}^{2}$ tissue flasks with $0.025 \%$ trypsin in $0.02 \%$ EDTA and splitting them 1:3. For experiments, all cultures were grown to confluency in 24well tissue culture plates in the presence of $10 \%$ FCS. The cells were harvested with a cell scraper (Beckton Dickinson, Lincoln Park, NJ) for RNA and protein analysis. The medium was changed to serum-free medium. After $48 \mathrm{~h}$, the culture medium was collected for measurement of the G-CSF and GM-CSF contents by ELISA, centrifuged at $1000 \mathrm{~g}$ for $10 \mathrm{~min}$ to remove cell debris and stored at $-80^{\circ} \mathrm{C}$. Each experiment was performed in triplicate.

Plasmids and DNA transfection. EcoRI-digested cDNA fragments of G-CSF or GM-CSF were ligated into the multiple cloning site of the expression vector pUSEamp and verified by restriction digests and sequence analysis. We named the sense G-CSF clone SG, the antisense G-CSF clone AG, the sense GM-CSF clone SGM, and the anti-sense GM-CSF clone AGM. pUSEamp without insert was used as a control clone and named Mock. DNA transfection was carried out using TransIT-LT1 transfection reagent. Subconfluent cells in a $60-\mathrm{mm}$ tissue culture dish were transfected with $5 \mu \mathrm{g}$ DNA in the presence of $15 \mu 1$ of TransIT-LT1 transfection reagent in $2 \mathrm{ml}$ of media containing 5\% FCS. At $48 \mathrm{~h}$ after transfection, the medium was changed to new one containing G418 as a selection marker. Clonal transfected populations were isolated. Successful transfection was confirmed by immunoblot analysis using anti-neomycin phosphotransferase II Ab.

Detection of G-CSF and GM-CSF. The concentrations of G-CSF or GM-CSF in the culture medium were determined using an ELISA kit according to the supplier's instructions. The sensitivities for these kits are 0.4 and $3.0 \mathrm{pg} / \mathrm{ml}$ for G-CSF and GM-CSF, respectively. The values of G-CSF and GM-CSF in the conditioned medium were expressed as $\mathrm{pg} / 10^{6}$ cells. G-CSF or GM-CSF levels in the fresh medium were less than the sensitivity for these kits.

$R T-P C R$. Total RNA was extracted from the cultured cells by the guanidine-thiocyanate method using Isogen solution (Nippon Gene Co., Tokyo). RNA (1 $\mu \mathrm{m})$ was converted to cDNA with Moloney murine leukemia virus reverse transcriptase in $20 \mu 1$ of reaction mixture. For quantification, $1 \mu 1$ aliquots of cDNA samples were subjected to PCR in $50 \mu 1$ of reaction solution containing $0.5 \mu \mathrm{M}$ of each specific primer, $10 \mathrm{mM}$ Tris- $\mathrm{HCl}, 50 \mathrm{mM} \mathrm{KCl}, 1.5 \mathrm{mM} \mathrm{MgCl}_{2}, 0.2 \mathrm{mM}$ dNTP, and 1 unit Taq polymerase. The G-CSF 328-bp fragment was detected by PCR $\left(30\right.$ cycles at $94^{\circ} \mathrm{C}$ for $1 \mathrm{~min}, 58^{\circ} \mathrm{C}$ for $1 \mathrm{~min}$ and $72^{\circ} \mathrm{C}$ for $1 \mathrm{~min}$ ) with $5^{\prime}$-TAGAGCAAGTGAGGAAGA TCCAGG-3' (forward primer) and 5'-AGTTCTTCCATCTG CTGCCAGATG-3' (reverse primer). The GM-CSF 424-bp fragment was detected by PCR $\left(30\right.$ cycles at $95^{\circ} \mathrm{C}$ for $1 \mathrm{~min}$, $60^{\circ} \mathrm{C}$ for $1 \mathrm{~min}$ and $73^{\circ} \mathrm{C}$ for $1 \mathrm{~min}$ ) with $5^{\prime}$-ATGTGGCTGC AGAGCCTGCTGC-3' (forward primer) and 5'-CTGGCT CCCAGCAGTCAAAGGG-3' (reverse primer). The G-CSF receptor 668-bp fragment was detected by PCR (30 cycles at $95^{\circ} \mathrm{C}$ for $55 \mathrm{sec}, 72^{\circ} \mathrm{C}$ for $70 \mathrm{sec}, 65^{\circ} \mathrm{C}$ for $95 \mathrm{sec}$, and one cycle of $435 \mathrm{sec}$ at $72^{\circ} \mathrm{C}$ ) with $5^{\prime}$-TGGACTGCAGCTGGT TTCAGGAAC-3' (forward primer) and 5'-GGTCTGACAGT TGCCCCGGCTC-3' (reverse primer). The GM-CSF receptor $\alpha$ 546-bp fragment was detected by PCR (30 cycles at $94^{\circ} \mathrm{C}$ for $1 \mathrm{~min}, 60^{\circ} \mathrm{C}$ for $1 \mathrm{~min}$ and $72^{\circ} \mathrm{C}$ for $1 \mathrm{~min}$ ) with $5^{\prime}$-CTTCTC TCTGACCAGCA-3' (forward primer) and 5'-ACATGGG TTCCTGAGTC-3' (reverse primer). The B-actin 309-bp fragment was detected by PCR $\left(20\right.$ cycles at $94^{\circ} \mathrm{C}$ for $1 \mathrm{~min}$, $58^{\circ} \mathrm{C}$ for $1 \mathrm{~min}$ and $72^{\circ} \mathrm{C}$ for $1 \mathrm{~min}$ ) with $5^{\prime}$-ACCTTCAACA CCCCAGCCATG-3' (forward primer) and 5'-GGCCATCT CTTGCTCGAAGTC-3' (reverse primer). PCR product (10 $\mu \mathrm{l}$ ) was electrophoresed on a $1 \%$ NuSieve GTG agarose gel and stained with ethidium bromide. Human G-CSF cDNA in pBRV2 and human GM-CSF cDNA in pCSF-1 were used as positive controls for the mRNA expression of G-CSF and GM-CSF. U937 and BALL-2 cells were used as positive and negative controls for the mRNA expression of G-CSF receptor or GM-CSF receptor $\alpha$ respectively. The identities of the PCR amplification products were confirmed by size and restriction digests. The intensity of the bands was evaluated using a UV-light box imaging system (Atto, Tokyo).

Western blot analysis. The medium was removed and cell monolayers were washed 3 times with ice-cold PBS and lysed in ice-cold buffer [50 mM Tris-buffered saline ( $\mathrm{pH} 8.0$ ), $150 \mathrm{mM} \mathrm{NaCl}, 0.002 \%$ sodium azide, $0.1 \%$ SDS, $100 \mu \mathrm{g} / \mathrm{ml}$ phenylmethylsulfonyl fluoride, $10 \mu \mathrm{g} / \mathrm{ml}$ leupeptin, $10 \mu \mathrm{g} / \mathrm{ml}$ pepstatin, $1 \mu \mathrm{g} / \mathrm{ml}$ aprotinin, $200 \mathrm{mM}$ sodium orthovanadate, $1 \%$ (octylphenoxy) polyethoxyethanol and $0.5 \%$ sodium 
A

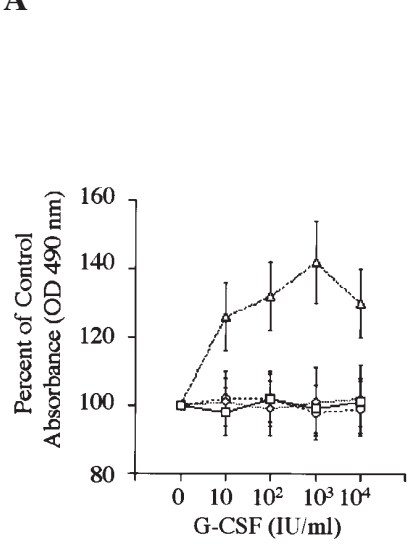

B

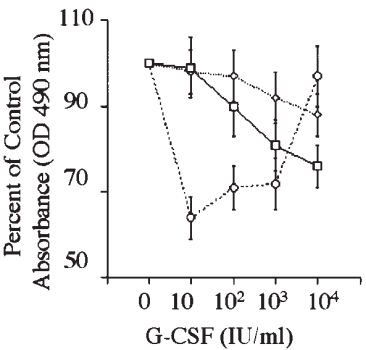

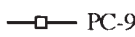

................ A549

……. LA-1

---

$\cdots \rightarrow---T^{-}$TF-1
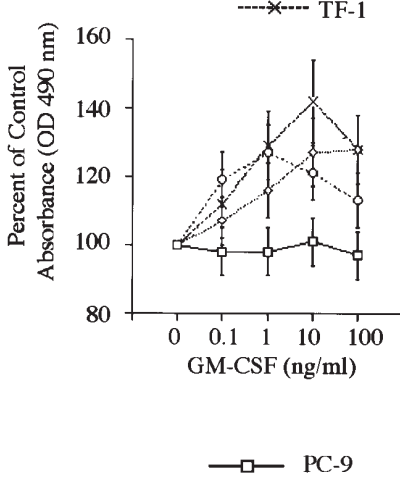

$\cdots \cdots \cdots \cdots \cdots \cdots$

$\cdots \cdot-\cdots \quad$ LA-1

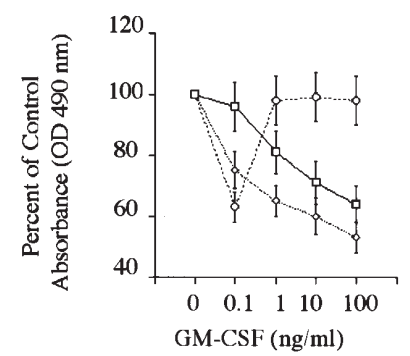

Figure 1. Effects of G-CSF and GM-CSF on cell growth and death. Cells were incubated with G-CSF $\left(0-10^{4} \mathrm{IU} / \mathrm{ml}\right)$ or GM-CSF $\left(0-10^{2} \mathrm{ng} / \mathrm{ml}\right)$ in media containing 1\% FCS for $48 \mathrm{~h}$. NFS-60 and TF-1 cells were used as positive controls for G-CSF and GM-CSF, respectively. (A) G-CSF did not stimulate cell growth in any cell line. GM-CSF dose-dependently stimulated cell growth in A549 and LA-1 cells, whereas it did not in PC-9 cells. (B) G-CSF and GM-CSF dose-dependently inhibited cell death in A549 and PC-9 cells, whereas it maximally inhibited cell death at a low dose in LA-1 cells. Results are given as the mean percentage $( \pm 1 \mathrm{SE})$ of the absorbance in each control.

deoxycholate] for $20 \mathrm{~min}$ on ice, followed by centrifugation at $4^{\circ} \mathrm{C}$ for $5 \mathrm{~min}$ to sediment the particulate material. The protein concentration of the supernatant was measured by a Bradford assay (Bio-Rad, Hercules, CA). Protein $(10 \mu \mathrm{g})$ was separated on $10 \%$ SDS-polyacrylamide gels and transferred onto nitrocellulose membranes (Bio-Rad). The membrane was blocked overnight at $4^{\circ} \mathrm{C}$ using I-block (Tropix, Bedford, MA). Membranes were incubated with 1:2000 dilutions of rabbit anti-neomycin phosphotransferase II $\mathrm{Ab}$ and mouse anti-COX-2 Ab and a 1:10,000 dilution of mouse anti- $B$-actin $\mathrm{Ab}$. Chemiluminescence was determined using the WesternStar kit (Tropix) according to the manufacturer's instructions.

Cell proliferation and cytotoxicity assay. Cells $\left(1 \times 10^{5}\right)$ were plated in 96-well plates and then cultured in serum-free medium for $24 \mathrm{~h}$ to deprive them of FCS. The medium was changed to a new one containing $1 \%$ FCS. After $48 \mathrm{~h}$ of incubation, a cell proliferation assay was performed using the 'Cell Titer 96' AQueous one solution cell proliferation assay kit (Promega). The absorbance of the solution was measured at $490 \mathrm{~nm}$ in a spectrophotometer. Released lactate dehydrogenase (LDH) in culture supernatants was measured using the 'Cyto Tox 96' cytotoxicity assay kit (Promega). The absorbance of the solution was measured at $490 \mathrm{~nm}$ in a spectrophotometer. The data represent the mean \pm SE of four wells from three independent experiments.

\section{Results}

Effects of exogenous G-CSF and GM-CSF on cell growth and death. After $48 \mathrm{~h}$ of serum deprivation, $70 \%$ confluent cells were incubated with various concentrations of G-CSF $\left(0-10^{4} \mathrm{IU} / \mathrm{ml}\right)$ and GM-CSF $\left(0-10^{2} \mathrm{ng} / \mathrm{ml}\right)$ in media containing $1 \%$ FCS. After $48 \mathrm{~h}$, cell growth and death were analyzed using cell proliferation and cytotoxicity assay kits. NFS-60 (ATCC CRL-1838) and TF-1 (ATCC CRL-2003) cells, which proliferate in response to G-CSF and GM-CSF, respectively, were used as positive controls. G-CSF did not influence cell growth in PC-9, LA-1 or A549 cells at any concentration. GM-CSF dose-dependently stimulated cell growth in LA-1 and A549 cells, while it did not influence PC-9 cells at any concentration. The maximal stimulatory effect of GM-CSF in A549 cells was observed at $1 \mathrm{ng} / \mathrm{ml}$ (Fig. 1A). Both G-CSF and GM-CSF decreased cell death in a dose-dependent manner in the three cell lines. The maximal effects of G-CSF and GMCSF were observed at $10 \mathrm{IU} / \mathrm{ml}$ and $0.1 \mathrm{ng} / \mathrm{m}$, respectively, in LA-1 cells (Fig. 1B). The data represent the mean \pm SE of four wells from three independent experiments.

Effect of a neutralizing human G-CSF Ab and a human GM$C S F A b$ on cell growth and death. To confirm the growth advantages of G-CSF and GM-CSF, cells were incubated with various concentrations of neutralizing human G-CSF mouse monoclonal $\mathrm{Ab}$ or human $\mathrm{GM}-\mathrm{CSF}$ goat $\mathrm{Ab}$ in the medium containing 1\% FCS. Mouse IgG1 isotype control and normal goat IgG were used as controls for anti-G-CSF Ab and antiGM-CSF Ab, respectively. NFS-60 and TF-1 cells, in which cell growth is decreased in response to anti-G-CSF Ab and anti-GM-CSF Ab, respectively, were used as positive controls. After serum deprivation, $70 \%$ confluent cells were incubated with various concentrations of anti-G-CSF Ab $(0-50 \mu \mathrm{g} / \mathrm{ml})$ and anti-GM-CSF $\mathrm{Ab}(0-10 \mu \mathrm{g} / \mathrm{ml})$ in the media containing $1 \%$ FCS. After $48 \mathrm{~h}$, cell growth and death were analyzed as described above. Anti-G-CSF Ab did not alter cell growth in the three cell lines, whereas anti-GM-CSF Ab dose-dependently inhibited cell growth (Fig. 2A).

Anti-G-CSF Ab also did not alter cell death in the three cell lines, whereas anti-GM-CSF Ab dose-dependently increased cell death (Fig. 2B). The data represent the mean \pm SE of four wells from three independent experiments.

Expression of G-CSF and GM-CSF receptors. Expression of the G-CSF receptor or GM-CSF receptor $\alpha$ was examined by RT-PCR in the cell lines. U937 cells were used as positive controls for both receptors and BALL-2 cells were used as negative controls. G-CSF receptor expression was detected in only PC-9 cells. GM-CSF receptor $\alpha$ was detected in PC-9, A549 and LA-1 cells (Fig. 3). Results are representative of three independent experiments. 
A

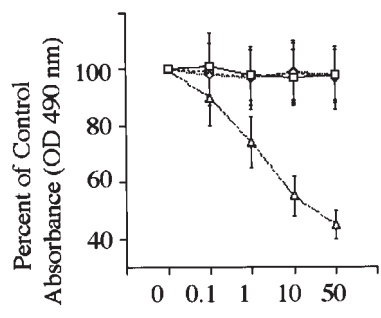

Anti-G-CSF Ab $(\mu \mathrm{g} / \mathrm{ml})$

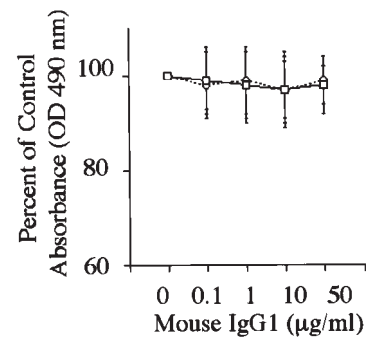

B
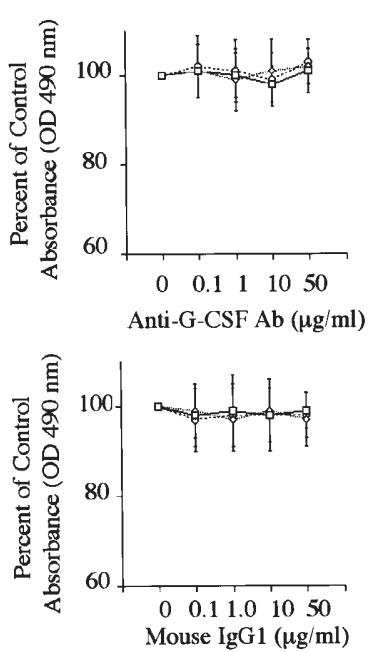

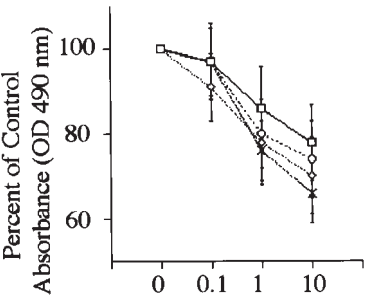

Anti-GM-CSF Ab $(\mu \mathrm{g} / \mathrm{ml})$
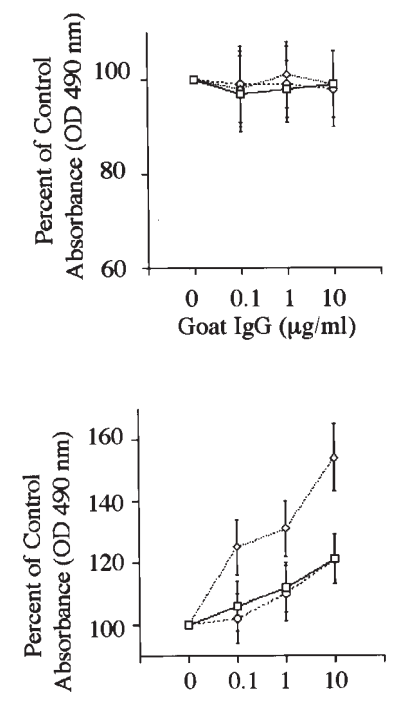

Anti-GM-CSF Ab $(\mu \mathrm{g} / \mathrm{ml})$

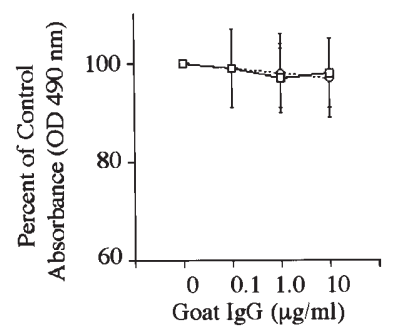

Figure 2. Effects of neutralizing antibodies of G-CSF and GM-CSF on cell growth and death. Cells were incubated with various concentrations of neutralizing antibodies for G-CSF $(0-50 \mu \mathrm{g} / \mathrm{ml})$ or GM-CSF $(0-10 \mu \mathrm{g} / \mathrm{ml})$ in media containing $1 \%$ FCS. Mouse IgG1 isotype control and normal goat $\mathrm{IgG}$ were used as negative controls for the G-CSF and GM-CSF antibodies, respectively. NFS-60 (ATCC CRL-1838) and TF-1 (ATCC CRL-2003) cells, whose growth is dose-dependently inhibited in response to neutralizing antibodies for G-CSF and GM-CSF, respectively, were used as positive controls. (A) G-CSF antibody did not inhibit cell growth at any concentration in PC-9, A549 and LA-1 cells. GM-CSF antibody dosedependently inhibited cell growth in the three lung cancer cell lines. (B) GCSF antibody did not inhibit cell death at any concentration in PC-9, A549 or LA-1 cells. GM-CSF antibody dose-dependently increased cell death in the three lung cancer cell lines. Results are given as the mean percentage $( \pm 1 \mathrm{SE})$ of the absorbance in each control.

Effects of G-CSF and GM-CSF on COX-2 expression. We examined the effect of exogenous G-CSF and GM-CSF on COX-2 expression in the cell lines. After $48 \mathrm{~h}$ of serum deprivation, 70\% confluent cells of A549 and PC-9 cells were incubated with $10^{3} \mathrm{IU} / \mathrm{ml} \mathrm{G}-\mathrm{CSF}$ or $10 \mathrm{ng} / \mathrm{ml} \mathrm{GM-CSF}$ in serum-free media and LA-1 were incubated with $10 \mathrm{IU} / \mathrm{ml}$ G-CSF or $0.1 \mathrm{ng} / \mathrm{ml} \mathrm{GM-CSF}$. After a $24 \mathrm{~h}$ incubation, cells were harvested and then assayed for COX-2 expression by Western blot analysis. Exogenous G-CSF and GM-CSF increased COX-2 expression in LA-1 and PC-9 cells, whereas they oppositely inhibited expression in A549 cells (Fig. 4).

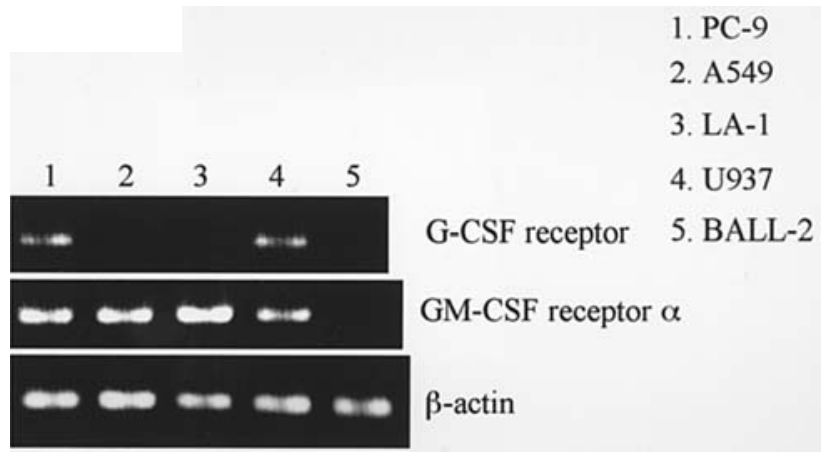

Figure 3. Expression of G-CSF receptor and GM-CSF receptor $\alpha$. RT-PCR demonstrated expression of G-CSF receptor in only PC-9 cells and GM-CSF receptor $\alpha$ in PC-9, A549 and LA-1 cells. Results are representative of three independent experiments.

\section{PC9}

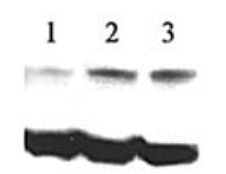

COX-2

1. control

2. G-CSF

3. GM-CSF

A549

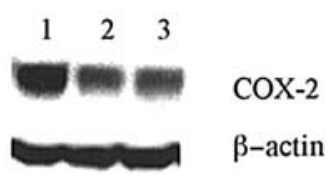

LA-1

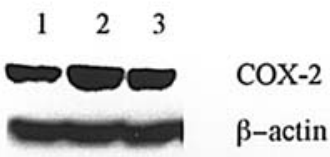

Figure 4. Effect of G-CSF and GM-CSF on COX-2 expression. After serum deprivation, A549 and PC-9 cells were incubated with $10^{3} \mathrm{IU} / \mathrm{ml}$ G-CSF or $10 \mathrm{ng} / \mathrm{ml} \mathrm{GM-CSF}$ in serum-free media, and LA-1 cells were incubated with $10 \mathrm{IU} / \mathrm{ml} \mathrm{G-CSF}$ or $0.1 \mathrm{ng} / \mathrm{ml}$ GM-CSF. After a $24 \mathrm{~h}$ incubation, harvested cells were analyzed for COX-2 expression by Western blot analysis. Both G-CSF and GM-CSF increased COX-2 expression in PC-9 and LA-1 cells, whereas they decreased expression in A549 cells. Results are representative of three independent experiments.

The data represent the mean \pm SE of four wells from three independent experiments.

Effect of the COX-2 inhibitor NS-398 on cell growth and cell death. We examined the effect of NS-398 on cell growth and cell death. After serum deprivation, the $70 \%$ confluent cells were incubated with various concentrations of NS-398 $(0-20 \mu \mathrm{M})$ in media containing $1 \%$ FCS. After $48 \mathrm{~h}$, cell growth and cell death were assayed by the methods described above. NS398 did not alter cell growth in PC-9, A549 or LA-1 cells, whereas it dose-dependently increased cell death in PC-9 and LA-1 cells. NS398 dose-dependently inhibited cell death in A549 cells (Fig. 5). The data represent the mean \pm SE of four wells from three independent experiments.

Transfection with G-CSF or GM-CSF cDNA and expression of these proteins and their receptors. Clonal transfected 


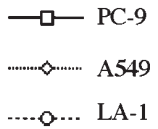

Growth
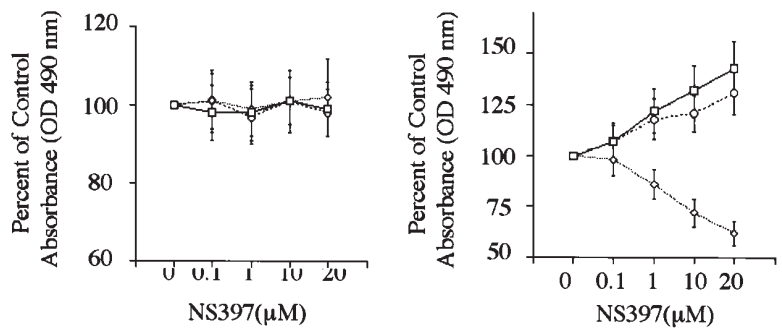

Figure 5. Effect of NS398 on cell growth and cell death. Cells were incubated with various concentrations of NS398 $(0-20 \mu \mathrm{M})$ in media containing $1 \%$ FCS. NS398 did not influence cell growth at any concentration in PC-9, A549 or LA-1 cells. NS398 dose-dependently increased cell death in PC-9 and LA-1 cells, whereas it decreased cell death in A549 cells. Results are given as the mean percentage $( \pm 1 \mathrm{SE})$ of the absorbance in each control.
PC-9

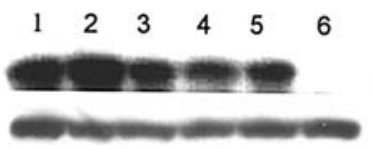

neomycin phosphotransferase II $\beta$-actin

A549

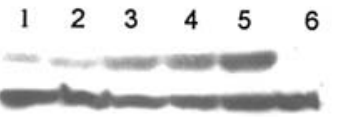

neomycin phosphotransferase I

$\beta$-actin

LA-1

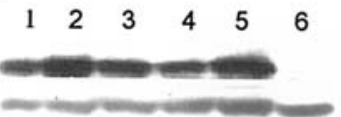

neomycin phosphotransferase II

$\beta$-actin

Figure 6. Transfection of cDNA fragments of G-CSF and GM-CSF. cDNA fragments of G-CSF or GM-CSF were ligated into the multiple cloning site of the vector pUSEamp. We named sense G-CSF transfected clone SG, antisense G-CSF AG, sense GM-CSF SGM, anti-sense GM-CSF AGM, and the control empty vector Mock. Transfection was confirmed by detection of neomycin phosphotransferase II by immunoblot analysis of transfected cells with anti-neomycin phosphotransferase II. Parent cells were used as a negative control in each cell line.

populations were isolated, and positive cell clones were identified by Western blot analysis using anti-neomycin phosphotransferase II Ab (Fig. 6). RT-PCR showed increased expression of G-CSF or GM-CSF in positive cell clones of each cell line (Fig. 7A and B). Messenger RNA expression data were confirmed by the protein levels in conditioned media using ELISAs for G-CSF and GM-CSF (Table I). Levels of G-CSF or GM-CSF that were constitutively produced by A549, LA-1 and PC-9 parent cells were $<10$ $\mathrm{pg} / 10^{6}$ cells. Sense clones of G-CSF and GM-CSF constitutively produced G-CSF and GM-CSF, respectively, in the three cell lines, whereas Mock transfectant and anti-sense
A

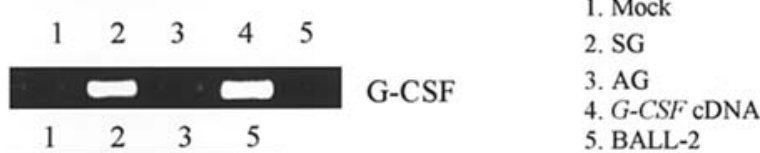

A549

$\cdots \infty$ G-CSF
\begin{tabular}{llll}
1 & 2 & 3 & 5 \\
\hline & $-\infty$ & $\beta$ & $\beta$
\end{tabular}

$\begin{array}{lllll}1 & 2 & 3 & 4 & 5\end{array}$

$\because \infty \quad, \quad \rightarrow \quad$ G-CSF

LA-1

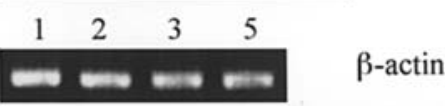

B

PC-9

2. SGM

3. AGM

4. GM-CSF CDNA

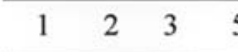

GM-CSF

5. BALL-2

$\beta$-actin

$\begin{array}{lllll}1 & 2 & 3 & 4 & 5\end{array}$

A549

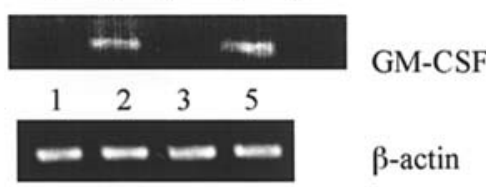

LA-1

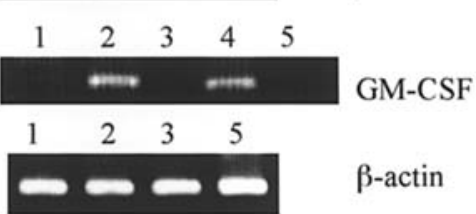

C

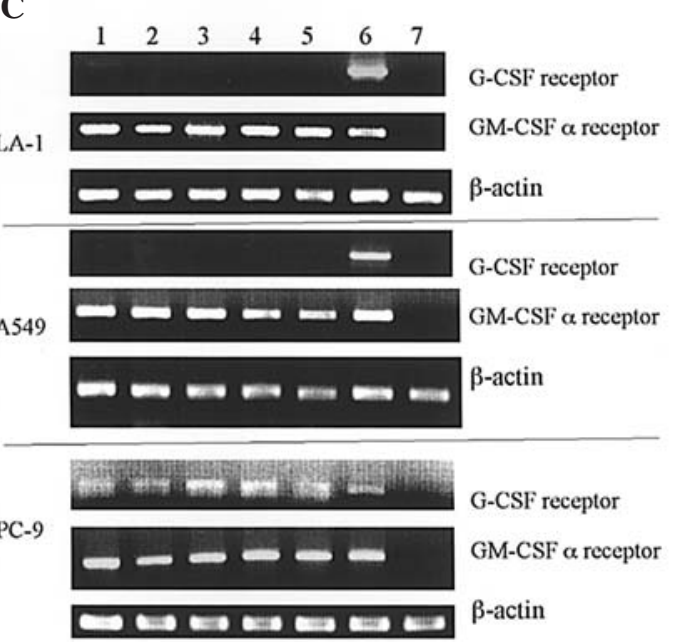

1. Mock

2. SG

3. AG

4. SGM

5. AGM

6. U937 cells

7. BALL-2 cells $\begin{array}{llllll}1 & 2 & 3 & 4 & 5 & 1 . \text { Mock }\end{array}$

Figure 7. Expression of G-CSF and GM-CSF in transfected clones. To examine whether G-CSF or GM-CSF would be successfully expressed in sense transfected clones, we checked their expression by RT-PCR. (A and B) RT-PCR showed increased expression of G-CSF or GM-CSF in sense clones in each cell line. Messenger RNA expression data were confirmed by the protein level in conditioned media using ELISA for G-CSF and GM-CSF (Table I). Results are given as the mean percentage $( \pm 1 \mathrm{SE})$ of the absorbance in each control. To confirm the maintenance of the G-CSF and GM-CSF receptor expression in the transfected clones, we analyzed the expression of these receptors by RT-PCR. (C) G-CSF receptor expression in PC-9 cells and GM-CSF receptor $\alpha$ in the three cell lines were maintained after transfection. Results are representative of three independent experiments. 

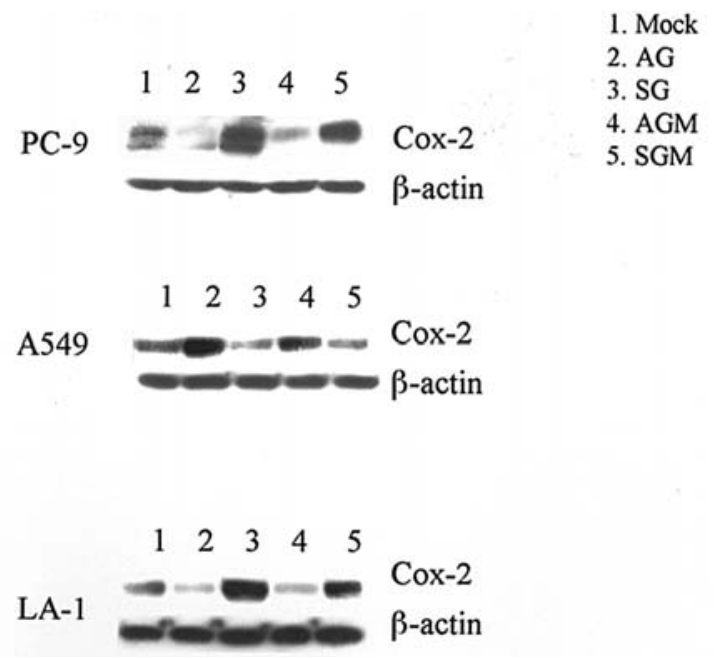

Figure 8. COX-2 expression in the transfected clones. COX-2 expression was increased in SG and SGM transfected clones of PC-9 and LA-1 cells, whereas it was decreased in $\mathrm{AG}$ and $\mathrm{AGM}$. It was increased in $\mathrm{AG}$ and AGM transfected clones of A549 cells, whereas it was decreased in SG and SGM. Results are representative of three independent experiments.
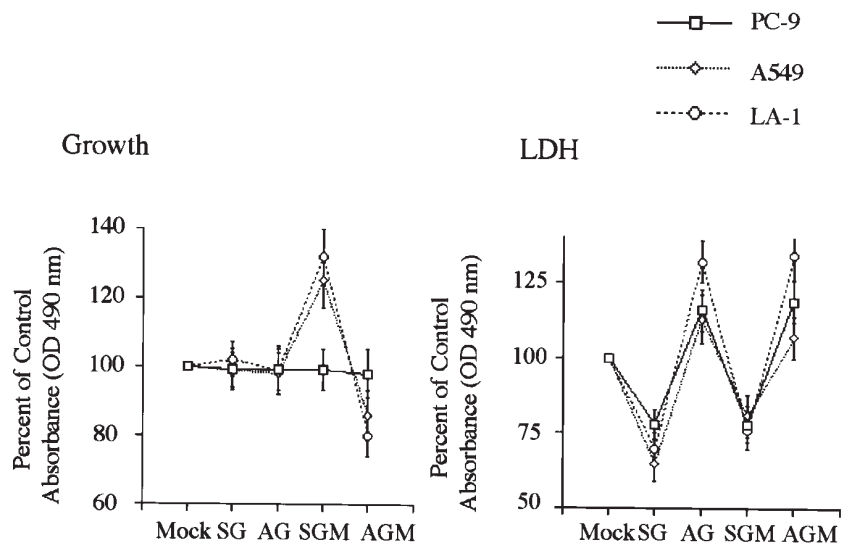

Figure 9. Cell growth and cell death in the transfected clones. Cell growth was not altered in SG and AG clones of PC-9, A549 and LA-1 cells. It was increased in SGM of A549 and LA-1 cells, whereas it was decreased in AGM. Cell death was decreased in SG and SGM in the three cell lines, whereas it was increased in AG and AGM. Results are representative of three independent experiments.

clones of G-CSF and GM-CSF did not. To confirm the maintenance of the G-CSF or GM-CSF receptor expression in the transfected clones, we analyzed the expression of these receptors by RT-PCR. G-CSF receptor expression in PC-9 cells and GM-CSF receptor $\alpha$ expression in each of the three cell lines was maintained even after transfection of each clone (Fig. 7C). The data represent the mean \pm SE of four wells from three independent experiments. Results are representative of three independent experiments.

COX-2 expression in the transfected clones. COX-2 expression was increased in SG and SGM transfected clones of PC-9 and LA- 1 cells, whereas it decreased in AG and AGM clones. It was increased in AG and AGM transfected clones of A549 cells, whereas it was decreased in SG and SGM (Fig. 8). Results are representative of three independent experiments.
Table I. Protein expression of G-CSF and GM-CSF.

\begin{tabular}{lccc}
\hline G-CSF (pg/10 cells) & \multicolumn{2}{l}{ GM-CSF (pg/10 } & cells) \\
\hline A549-Mock & PB & A549-Mock & PB \\
A549-AG & PB & A549-AGM & PB \\
A549-SG & $120 \pm 11$ & A549-SGM & $310 \pm 21$ \\
LA-1Mock & PB & LA-1Mock & PB \\
LA-1AG & PB & LA-1AGM & PB \\
LA-1SG & $210 \pm 18$ & LA-1SGM & $410 \pm 51$ \\
PC-9-Mock & PB & PC-9-Mock & PB \\
PC-9-AG & PB & PC-9-AGM & PB \\
PC-9-SG & $187 \pm 14$ & PC-9-SGM & $280 \pm 28$ \\
\hline
\end{tabular}

$\mathrm{PB}$, protein below detection level.

Cell growth and cell death in the transfected clones. Cell growth and death were assayed as described above. Cell growth was not influenced in SG and AG transfected clones of PC-9, A549 or LA-1 cells. SGM transfected clones of A549 and LA-1 cells had a growth advantage. Cell death of both SG and SGM transfected clones decreased in PC-9, A549 and LA-1 cells, whereas in AG and AGM it increased (Fig. 9).

\section{Discussion}

It is known that the prognosis is significantly worse in patients with non-small-cell lung cancer (NSCLC) showing G-CSF gene expression (7). Several studies have demonstrated the presence of an autocrine growth loop for G-CSF or GM-CSF in nonhematopoietic tumor cells involving lung cancer (12-15). Exogenous G-CSF and GM-CSF also stimulate invasion by lung cancer cells as well as their endogenous counterparts $(16,17)$. These studies indicate that tumor progression might be critically controlled by alterations in the microenvironment often caused by an aberrant expression of growth factors and receptors. However, a G-CSF autocrine loop is not necessarily involved in the growth of these G-CSFproducing tumors (10), suggesting that exogenous G-CSF or endogenous G-CSF gene expression might progress tumor growth by mechanisms besides an autocrine growth loop.

In our study, exogenous and endogenous GM-CSF increased cell growth and decreased cell death in PC-9, LA-1 and A549 cells. The three cell lines expressed the GM-CSF receptor, suggesting that they might have a growth advantage via an autocrine growth loop for GM-CSF. Exogenous and endogenous G-CSF decreased cell death in the three cell lines, but could not, however, influence cell growth. We were not able to demonstrate the presence of the G-CSF receptor in A549 and LA-1 cells by RT-PCR. These results suggested that inhibition of cell death by G-CSF might be induced through mechanisms independent of the G-CSF receptor in the cell lines.

Many studies report that COX-2 inhibitors can inhibit tumor progression through several pathways, for example matrix metalloproteinase or mitogen-activated proteinkinase/ 
ERK (18-20). We previously showed that COX-2 activity might be closely associated with tumor growth via an autocrine growth loop for G-CSF and GM-CSF in lung cancer (11). COX-2 expression was activated by exogenous stimulation and endogenous expression of G-CSF and GM-CSF in PC-9 and LA-1 cells. Although NS398 did not influence cell growth in the three cell lines, it increased cell death in PC-9 and LA-1 cells. G-CSF and GM-CSF transfected clones of PC-9 or LA-1 cells also showed increased COX-2 expression, resulting in inhibition of cell death. G-CSF and GM-CSF decreased COX-2 expression in A549 cells and, in addition, NS398 decreased cell death. COX-2 expression was increased in anti-sense clones of G-CSF and GM-CSF in A549 cells, whereas it was decreased in the sense-clones of A549 cells. Duan et al reported that NS398 $(0.2-20 \mu \mathrm{M})$ was not able to inhibit A549 cell proliferation, on the contrary, NS398 promoted cell growth (21). Although we could not show a growth effect for NS398 in A549 cells, NS398 appeared to inhibit cell death, resulting in increased tumor progression. Thus, we proved that exogenous and endogenous G-CSF and GM-CSF could regulate cell growth and death via COX-2 expression. In particular, the inhibitory effect of G-CSF on cell death appeared to be induced regardless of G-CSF receptor expression in some types of lung cancer. However, it is not clear whether the inhibitory effect of NS398 on cell death is restricted to A549 cells or a common phenomenon in lung cancer. It is known that GM-CSF promotes tumor growth via an autocrine mechanism in lung cancer (14). In our study, GM-CSF also had a growth advantage through COX-2 expression. However, it is not clear whether GM-CSF could also induce COX-2 expression without the aid of the GM-CSF receptor because we did not examine this using cell lines lacking the GM-CSF receptor in this study. To clarify whether the biological effect of NS398 is dependent on cell type and whether the effects of G-CSF and GM-CSF on COX-2 expression are independent of the receptors for each, many more types of lung cancer cells need to be examined.

\section{References}

1. Hida T, Yatabe Y, Achiwa H, et al: Increased expression of cyclooxigenase 2 occurs frequently in human lung cancers, specifically in adenocarcinomas. Cancer Res 58: 3761-3764, 1998.

2. Achiwa H, Yatabe Y, Hida T, et al: Prognostic significance of elevated cyclooxygenase 2 expression in primary, resected lung adenocarcinomas. Clin Cancer Res 5: 1001-1005, 1999.

3. Chang HC and Weng CF: Cyclooxygenase-2 level and culture conditions influence NS398-induced apoptosis and caspase activation in lung cancer cells. Oncol Rep 6: 1321-1325, 2001.

4. Asano S, Urabe A, Okabe T, Sato N and Kondo Y: Demonstration of granulopoietic factor(s) in the plasma of nude mice transplanted with a human lung cancer and in the tumor tissue. Blood 49: 845-852, 1977

5. Okabe T, Sato N, Kondo Y, Asano S, Ohsawa N, Kosaka K and Ueyama Y: Establishment and characterization of a human cancer cell line that produces human colony-stimulating factor. Cancer Res 38: 3910-3917, 1978.
6. Ueyama $\mathrm{Y}$ and Tamaoki N: Leukocytosis in nude mice into which human tumors are transplanted: in vivo screening system for hematopoietic growth factors in human tumors. In: Hematopoietic Growth Factors: Molecular Biology to Clinical Applications of rG-CSF. Quesenberry PJ, Asano S and Saito S (eds). Excerpta Medica, Tokyo, pp27-53, 1991.

7. Kasuga I, Makino S, Kiyokawa H, Katoh H, Ebihara Y and Ohyashiki K: Tumor-related leukocytosis is linked with poor prognosis in patients with lung carcinoma. Cancer 92: 2399-2405, 2001.

8. Young MR, Charboneau S, Lozano Y, Djordjevic A and Young ME: Activation of the protein kinase a signal transduction pathway by granulocyte-macrophage colony stimulating factor or by genetic manipulation reduces cytoskeletal organization in Lewis lung carcinoma variants. Int J Cancer 56: 446-451, 1994.

9. Uemura Y, Kobayashi M, Nakata H, Harada R, Kubota T and Taguchi H: Effect of serum deprivation on constitutive production of granulocyte-colony stimulating factor and granulocyte macrophage-colony stimulating factor in lung cancer cells. Int $\mathbf{J}$ Cancer 109: 826-832, 2004.

10. Tani K, Ozawa K, Ogura H, et al: Expression of granulocyte and granulocyte-macrophage colony-stimulating factors by human non-hematopoietic tumor cells. Growth Factors 3: 325-331, 1990.

11. Nakata H, Uemura Y, Kobayashi M, Harada R and Taguchi H: Cyclooxygenase-2 inhibitor NS-398 suppresses cell growth and constitutive production of granulocyte-colony stimulating factor and granulocyte macrophage-colony stimulating factor in lung cancer cells. Cancer Sci 94: 173-180, 2003.

12. Miyagawa K, Chiba S, Shibuya K, et al: Frequent expression of receptors for granulocyte-macrophage colony-stimulating factor on human nonhematopoietic tumor cell lines. J Cell Physiol 143: 483-487, 1990.

13. Tachibana M, Miyakawa A, Tazaki H, et al: Autocrine growth of transitional cell carcinoma of the bladder induced by granulocyte-colony stimulating factor. Cancer Res 55: 3438-3443, 1995.

14. Oshika Y, Nakamura M, Abe Y, et al: Growth stimulation of non-small cell lung cancer xenografts by granulocyte-macrophage colony-stimulating factor (GM-CSF). Eur J Cancer 34: 1958-1961, 1998.

15. Obermueller E, Vosseler S, Fusenig NE and Mueller MM: Cooperative autocrine and paracrine functions of granulocyte colony-stimulating factor and granulocyte-macrophage colonystimulating factor in the progression of skin carcinoma cells. Cancer Res 64: 7801-7812, 2004.

16. Pei XH, Nakanishi Y, Takayama K, et al: Granulocyte-colony stimulating factor promotes invasion by human lung cancer cell lines in vitro. Clin Exp Metastasis 14: 351-357, 1996.

17. Nachbaur D, Denz H, Zwierzina H, Schmalzl F and Huber H: Stimulation of colony formation of various human carcinoma cell lines by rhGM-CSF and rhIL-3. Cancer Lett 50: 197-201, 1990.

18. Byun JH, Lee MA, Roh SY, et al: Association between Cyclooxygenase-2 and matrix metalloproteinase-2 expression in non-small cell lung cancer. Jpn J Clin Oncol 36: 263-268, 2006.

19. Krysan K, Reckamp KL, Dalwadi H, Sharma S, Rozengurt E, Dohadwala $M$ and Dubinett SM: Prostaglandin E2 activates mitogen-activated protein kinase/Erk pathway signaling and cell proliferation in non-small cell lung cancer cells in an epidermal growth factor receptor-independent manner. Cancer Res 65: 6275-6281, 2005.

20. Han S and Roman J: COX-2 inhibitors suppress integrin alpha5 expression in human lung carcinoma cells through activation of Erk: involvement of Sp1 and AP-1 sites. Int J Cancer 116: 536-546, 2005.

21. Duan W and Żhang L: Cyclooxygenase inhibitors not inhibit resting lung cancer A549 cell proliferation. Prostaglandins Leukot Essent Fatty Acids 74: 317-321, 2006. 